\title{
Universal Design Patterns for stoma care away-from-home
}

Hubert Froyen ${ }^{1}$, Evelien Verdonck², Dirk De Meester ${ }^{3}$ and Ann Heylighen ${ }^{4}$

${ }^{1}$ Department of Architecture, PHL, Diepenbeek, and Ghent University, Belgium

2 Department of Architecture, PHL, Diepenbeek, and Hasselt University, Belgium

${ }^{3}$ Department of Architecture and Urban Planning, Ghent University, Belgium

${ }^{4}$ Department of Architecture, Urbanism \& Planning, K.U.Leuven, Belgium

\section{RESEARCH}

Please cite this paper as: Froyen $\mathrm{H}$, Verdonck $\mathrm{E}$, De Meester $D$, and Heylighen A. Universal design patterns for stoma care away-from-home. AMJ 2009, 1, 13, 213-216 Doi 10.4066/AMJ.2009.159

Corresponding Author:

Hurbert Froyen

Professor of Architecture

Department of Architecture, Diepenbeek (B)

University Campus, Building E, B-3590

Diepenbeek, Belgium

HFroyen@mail.phl.be

Abstract

Accommodating the real diversity of user populations, including those with physical and / or mental impairments and functional limitations, requires a large amount of design information in connection with human dis-abilities (limitations and possibilities). In order to collect and organise this information for designers and decision makers, Universal Design Patterns (UD Patterns) offer descriptive information about, on the one hand, CONFLICTS between users and built environments, and on the other hand, empirically evident design RESOLUTIONS. Direct collaboration with users / experts was tested in the development of a specific UD Pattern for a (Semi-) ambulant accessible toilet for personal care, with specific emphasis on stoma-care in public facilities. The paper illustrates how people with ostomies and care-givers communicate with researchers, and how relevant design information is extracted and structured. On a more general level, results show how environment-related dimensions of human functioning differ from medical aspects, and how direct involvement of end-users enriches the content of design information.

Key words: accessibility, disability, evidence-based design, stoma care, Universal Design, Universal Design Patterns, users / experts

\section{Introduction}

Including the real diversity of user populations in the design of the built environment requires a large amount of design information in connection with human dis-abilities (limitations and possibilities). In order to collect and organise this information for decision makers and designers, we advance Universal Design Patterns [1] as key elements in the process of the systematic elimination of handicap situations in the built environment [2]. By way of example, a search was made into major design aspects for toilet facilities for stoma care away-from-home. Contrary to the incredible amount and diversity of architectonic aspects and elements, potentially responsible for disabling built environments, the disability of people who use urostomy and colostomy bags is centred on toileting, often involving a frequent and urgent need to use a toilet to empty or change their bag [3]. This is a primary reason for the strategic choice of this clearly delimited research theme of 'conflicts' and 'resolutions' for stoma care. A second reason is that colostomy manifests itself in the social area as 'a hidden disability' and that designers cannot distil data from first principles from informal observations of the persons involved. A third reason is that comprehensive generic design information in connection with this theme is also lacking, for example, in architectural design guides [4], and also in the many printed and digital 'Patient's Guides to Colostomy Care'. Exceptions, such as the recent The Accessible Toilet Resource [3], confirm this situation.

\section{Methods}

The limited research into relevant architectural design aspects for spaces and facilities for stoma care away-fromhome was carried out in Belgium in the period July to December 2008. A literature search on relevant architectural design aspects included medical and paramedical sources of information. In August 2008 these design aspects were discussed with care-giver $\mathrm{TL}$ (Enterostomal Therapist) and the facilities for stoma care in Imelda Hospital, Bonheiden were analysed. On location, discussions were conducted with hospitalised persons with ostomies (female, 40 yrs., ileostomy; male 75 yrs., colostomy). As a consequence, the list of relevant design aspects was adapted and expanded. In September 2008 the tentative research data were presented orally to the local Ostomy Association Keerbergen, with 40 persons with ostomies and their spouses / significant others in the audience. A questionnaire that was handed out, which listed and described relevant architectural design aspects was answered anonymously by 18 persons with ostomies. Discussions were conducted with two persons present with 
stoma (female, 45 yrs., male, 50 yrs., and colostomy). On the basis of data collected, the list of relevant design aspects was adjusted again, and then, in December of 2008, was discussed with care-giver GB (Enterostomal Therapist), VJZ Hospital, Hasselt. The pilot study was announced and the questionnaire was published in the VLAS newsletter of the regional Enterostomal Therapist association [5]. Next we developed a concept plan in which the requested aspects and elements for stoma care are arranged spatially and visualised. For the graphic presentation of the concept plan use was made of a photo-realistic reproduction in renderings, in order to further optimise discussions with users / experts (non-architects). Via Enterostomal Therapist $\mathrm{GB}$, this concept plan was sent to a contact person with ileostomy. The lady (ileostomy) responded in writing and by telephone.

\section{Results and Discussion}

Among the 18 anonymous respondents, there are 14 persons with Colostomy, 3 persons with lleostomy and 1 person with Urostomy. The following types of facilities and comments were mentioned.

\begin{tabular}{|c|c|c|}
\hline Type of facility & $\begin{array}{l}\text { No. of } \\
\text { mentions }\end{array}$ & Comments \\
\hline Clothing hooks & 13 & - several clothing hooks \\
\hline Shelf & 13 & - preferably close to washbasin \\
\hline Washbasin & 13 & \\
\hline Extra paper & 12 & \\
\hline Mirror & 10 & - mirror at body height \\
\hline Rubbish bin with lid & 13 & \\
\hline Good lighting & 14 & \\
\hline Good ventilation & 14 & \\
\hline Other (open question) & & $\begin{array}{l}\text { - dispenser with WC fixture } \\
\text { cleaner, } \\
\text { - pictograms, } \\
\text { - signposting to wc, } \\
\text { - disposal bags in men's toilet as } \\
\text { well, } \\
\text { - cubicle open as little as } \\
\text { possible (cf. swimming pools), } \\
\text { - door that can be firmly locked } \\
\text { with a clear indication of its } \\
\text { being locked, } \\
\text { - toilet brush, } \\
\text { - Sturdy chair. }\end{array}$ \\
\hline
\end{tabular}

Figure 1. Survey results

In the renderings of (Semi-) ambulant accessible toilets below, the relevant results (aspects and elements) of the pilot study are integrated in a synthesis of architectural form. The objective was not to design an actually usable toilet or to present a typical solution, but to work out the next step in the Universal Design research project.

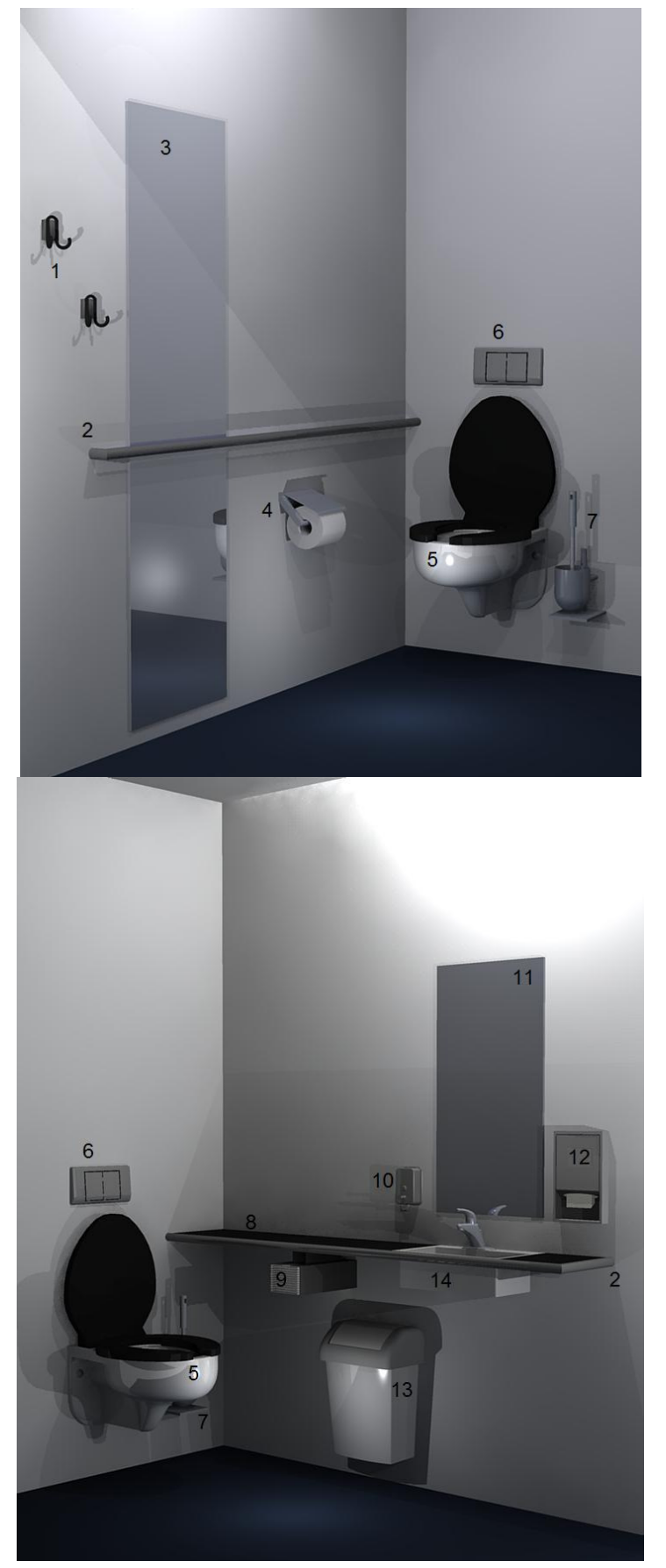

Architectural Design: Hubert Froyen. Illustration: Wim Dirickx (C) 2009

Figure 2. Preliminary hypothetical design for a (Semi-) ambulant accessible toilet for personal care.

1. Clothing hooks, 2. Support elements left, 3. Mirror at body height, 4. WC paper, 5. WC fixture,

6. Toilet flush, 7. Toilet brush, 8. Shelf, 9. Sanitary bags, 10. Soap dispenser, 11. Mirror, 12. Paper dispenser, 13. Rubbish bin, 14. Washbasin with warm and cold water and a onehand mixing tap.

The above data from the limited questionnaire are essential in compiling a list of facilities, but especially the added comments give the designers more insight into the 'why' and 'how' of the requested elements. General requests such as 'good lighting', 'wc open as little as possible', 'door that can be firmly locked with a clear indication of its being locked', are important for all users, but gain specific 
meaning in the stories of actual users / experts, in this case persons with ostomies.

MV (female, ileostomy, interview 27 April 2009) mentions among other things:

- 'As a person with ileostomy I usually kneel at the wc fixture to let the bag empty out. My feet and legs can then be seen if the bottom of the door is open.'

- 'Sometimes I also take my skirt off and then I need sufficient clothing hooks.'

- 'A sufficiently large rubbish bin is more important than having sanitary bags available because bags can be brought along. Half of the population is female and carries a handbag.'

- 'Good ventilation is very important to increase privacy and avoid stigma.'

During the initial research (July to December 2008) several important limitations and lacunas were discovered with regard to the target group, method of communication and of processing the research data in the UD Patterns. By concentrating the research subproject on people with stoma, insufficient specific attention is currently being given to the primary target group of semi ambulant users, and for the remaining users with other motor, sensory and mental limitations. The method of communication was diverse (oral, in writing, lecture, anonymous questionnaire, publications, telephone, graphics), but elements such as the floor plan included in the questionnaire were only used by 7 of the 18 respondents in their answers, 11 of the 18 made no notes whatever on the floor plan. This suggests that suitably adapted media and styles are needed for designcentred communication with users / experts (nonarchitects). In this phase of research a gap remains between the detailed design data in function of a specific target group and one type of architectonic space ('the disability of people who use urostomy and colostomy bags is centred on toileting'), and the processing of specific research data in global UD Patterns for a diversity of users (with needs and desires that are often contradictory) and for the real complexity of built environments.

\section{Conclusions and future work}

An important goal in our overall methodological approach, and more particularly in the UD Pattern research project, is to find efficient ways of dealing with design information related to the functional effects of human disabilities and activity limitations, without getting tangled in medical jargon or non-relevant and often compromising confidential medical information. The paper illustrates how people with ostomies and care-givers communicate with researchers, and how relevant design information is extracted and structured. This design information is tentative, and we view the proposed UD Patterns for the built environment not only as carriers of information, but also as Open Content forums and as tools in the on-going search for temporal social, academic and professional consensus [2].

Direct involvement of end-users is essential in the search for social consensus, and participation enriches the content of design data. With the limited scope and results of the pilot study, it is hard to draw general conclusions. However, the process of communication between people with ostomies / care-givers and researchers, and the gradual building up of data for Conflicts and Resolutions has provided some insights into the problems, and could help direct the focus of future work. Plans for follow-up research include: distribution of the first hypothetical design for a (Semi-) ambulant accessible toilet for personal care, for critical analysis and feedback from users / experts and from designers and decision makers; integration of the critical objections and suggestions in a second hypothetical design; and construction of a mock-up ( $100 \%$ scale model) for 'in vivo' tests with a diversity of users with physical, sensory and mental limitations.

\section{ACKNOWLEDGEMENTS}

The authors would like to thank the Enterostomal Therapists, Theo Leysen (Imelda Hospital, Bonheiden, B) and Guy Bylois (VJZ Hospital, Hasselt, B), Guido De Ron, president of the local Ostomy Association Keerbergen, and all people with ostomies who participated either in the discussions or in the anonymous questionnaire.

We also thank Roy Davison who provided partial translation and language correction, and Wim Dirickx for the information graphics.

\section{Reference}

1. Froyen $H$, Verdonck $E$, De Meester D, and Heylighen A. Documenting handicap situations and eliminations through Universal Design Patterns. AMJ 2009, 1, 12, 199-203. Doi 10.4066/AMJ.2009.158

2. Froyen $\mathrm{H}$ : Universal design patterns and their use in designing inclusive environments. In: Langdon P, Clarkson J, Robinson $\mathrm{P}$, eds. Designing inclusive futures. Londen: Springer; 2008; 249-260.

3. Hanson J, Bichard J-A, Greed C: The accessible toilet resource. Research Report. Londen: UCL, 2007.

4. Neufert E: Bauentwurfslehre. Wiesbaden: Vieweg Verlag; 2005.

5. Leysen T, Froyen H: Help, help. VLAS, Contactblad Vlaamse Stomaverpleegkundigen 2008, 14(2): 55-57.

\section{PEER REVIEW}

Not commissioned; externally peer reviewed

\section{CONFLICTS OF INTEREST}

The author(s) declare that they have no competing interests.

\section{AUTHORS' CONTRIBUTIONS}

$\mathrm{HF}$ conducted the literature review, did the data collection and composed the article.

EV has been involved in drafting and revising the manuscript.

DDM participated in the supervision of the research reported here.

$\mathrm{AH}$ participated in the supervision of the study reported here and in the writing of the article (content and structure). All authors read and approved the final manuscript. 